\title{
A PRIVACIDADE NO AMBIENTE CIBERNÉTICO: DIREITO FUNDAMENTAL DO USUÁRIO
}

\section{PRIVACY IN THE CYBERNETIC ENVIRONMENT: FUNDAMENTAL LAW FOR THE USER}

\author{
Waleska Duque Estrada Vieira ${ }^{1}$
}

Resumo: O presente artigo tem como objetivo analisar o direito à privacidade no mundo cibernético, em face das informações pessoais dos próprios usuários que utilizam as redes sociais. Para que exista um entendimento acerca do direito abordado, analisa primeiramente a privacidade como um direito do indivíduo. Discorre sobre a privacidade nas redes sociais e os impactos que podem causar no cotidiano dos usuários, em caso de violação desse direito. Por fim, faz uma explanação sobre a Lei do Marco Civil da Internet, que surgiu com o objetivo de regulamentar o uso da Internet no Brasil, assegurar a proteção da privacidade no ambiente cibernético.

Palavras-chave: Direito à privacidade. Redes sociais. Lei do Marco Civil da Internet.
Abstract: This article aims to analyze the right to privacy on the cyber world, due to the spreading of personal information of the users of social networks. In order to create an understanding of the right at issue, it first analyzes privacy as an individual right. It talks about privacy in social networks and the issues they can create in the daily life of users, in case of violation of this right. Finally, it enlighten usabout the Brazilian legislation called "Marco Civil da Internet" which is a law specifically created on the issue, which arose with the purpose of regulating the use of the internet in Brazil, to ensure the protection of people's privacy in the cybernetic environment.

Keywords: Right to privacy. Social networks. Marco Civil da Internet.

\section{INTRODUÇÃO}

Nos últimos tempos, os avanços tecnológicos da informa-

1 Aluna da Escola Superior da Magistratura do Estado de Santa Catarina (Esmesc). Especialista em Direito Constitucional e Processo Constitucional pela Universidade Estadual do Ceará (UECE). MBA em Gestão de Comércio Exterior e Negócios Internacionais pela Fundação Getúlio Vargas (FGV). Graduação em Administração Comércio Exterior pela Centro Universitário do Pará (CESUPA). Advogada. E-mail: waleskaduqueestrada@hotmail.com 
ção vêm revolucionando a vida do indivíduo em sociedade numa rapidez que preocupa até mesmo os estudiosos do assunto, isso porque o ingresso desses avanços tecnológicos não trouxe somente fatores positivos, mas também fatores negativos que chegam a prejudicar a convivência em sociedade, vitimizando pessoas-cidadãos famosos ou anônimos, quando se encontram na condição de usuários da WEB - Rede Mundial de Computadores que tem a sua configuração na Internet e, mais recentemente, nas Redes Sociais.

Um dos aspectos negativos que preocupa o usuário do ambiente virtual é a invasão das informações/dados/figuras pessoais que, na maioria das vezes, são divulgados pela Internet sem o consentimento deste, ocasionando a inviolabilidade de sua privacidade no mundo cibernético.

É seguindo este percurso e com o intuito de manter-se atual e atuante que a Constituição Federal (CF), 1988, destaca no seu art. $5^{\circ}$, inciso $X$, a proteção ao direito da privacidade e à intimidade do indivíduo, instituindo garantias quando da violação destes direitos, os quais convergem para a relevância e prevalência da dignidade da pessoa humana.

Considerando a dinamicidade do direito, este procura se ajustar à contemporaneidade e passa a tratar do direito à privacidade dos que se movimentam no espaço cibernético e se veem diante de dilemas decorrentes do confronto tecnológico em face da interferência do direito à privacidade do indivíduo.

Mesmo disponibilizando dados/informações/figuras, fotos etc. em algum site da Internet, ou, mais especificamente, por meio das Redes Sociais, com destaque para o Facebook, e-mail, Instagram, WhatsApp, o espaço cibernético tem exposto os seus usuários ao permitir a violação de dados/figuras/ informações pessoais, mesmo que esses tenham contribuído para esta realidade, ao não se preocuparem com o fator segurança, para a preservação da sua privacidade e dignidade 
humana. Por outro lado, as próprias empresas provedoras não estão muito preocupadas em prover, sobretudo, a segurança do seu cliente/usuário tendo em vista a exigência de grandes investimentos nesse sentido.

Assim, tem-se como questionamento se existe alguma norma específica que proteja a privacidade das informações dos usuários no ambiente ambiental, principalmente nas redes sociais?

Por essa razão, o estudo destina-se especificamente a discutir como os usuários podem proteger a sua privacidade face ao ambiente virtual, principalmente nas redes sociais e verificar como os Tribunais Brasileiros vêm recepcionando a violação do direito à privacidade das informações no mundo digital.

Espera-se que este estudo, possa ajudar os usuários que navegam na Internet, a proteger as suas informações privadas contra as invasões de terceiros mal-intencionados, e, sobretudo, demonstrar a importância desse direito para a vida de cada indivíduo.

\section{PRIVACIDADE COMO UM DIREITO DO INDIVÍDUO}

A palavra privacidade é apontada como um anglicismo de privacy que tem raiz no termo latim privare. Entretanto, a palavra privacidade não possui um conceito objetivo e único, tendo vários posicionamentos doutrinários quanto ao seu significado, podendo estes serem mais abrangentes ou mais restritos (ASSIS, 2015).

Dentre essas doutrinas está a Teoria das Esferas de Robert Alexy (2002, apud MARQUES, 2008, p.1)onde este destaca três níveis de proteção à vida privada, com decrescente intensidade de proteção, quais sejam:

A esfera mais interna, caracterizando-se por ser o âmbito mais íntimo, a esfera íntima intangível, o âmbito núcleo 
absolutamente protegido da organização da vida privada, compreendendo os assuntos mais secretos que não devem chegar ao conhecimento dos outros devido à sua natureza extremamente reservada; a esfera privada ampla, que abarca o âmbito na medida em que não pertença à esfera mais interna, incluindo assuntos que o indivíduo leva ao conhecimento de outra pessoa de sua confiança, ficando excluído o resto da comunidade; e a esfera social, que engloba tudo o que não for incluído na esfera privada ampla, ou seja todas as matérias relacionadas com as notícias que a pessoa deseja excluir do conhecimento(s) de terceiros.

Entende-se, pois, que o direito à privacidade, como ensina Marques (2008), nada mais é do que aquilo que nos preserva do conhecimento alheio, reserva-nos a nossa própria vivência.

De forma ampla, a privacidade está relacionada com o direito subjetivo e inerente a cada indivíduo, no qual abrange o modo de vida doméstico, às relações familiares e afetivas, os hábitos, o nome, a imagem, os pensamentos e os segredos nas mais diversas situações.

Lafer (1998, apud MACEIRA, 2012, p. 50) considera o conceito de privacidade não apenas como "direito do indivíduo de estar só", mas também "[...] a possibilidade que deve ter toda pessoa de excluir do conhecimento de terceiros aquilo que só se refere a ela e que diz respeito ao seu modo de ser no âmbito da vida privada".

Nessa mesma linha de pensamento, Bastos (2000. p.56), com uma visão constitucionalista, define a privacidade como sendo:

A faculdade que tem cada indivíduo de obstar a intromissão de estranhos em sua vida privada e familiar, assim como de impedir-lhes o acesso a informações sobre a privacidade de cada um, e também impedir que sejam divulgadas informações sobre esta área da manifestação existencial do ser humano.

Nesse contexto, verifica-se que o direito à privacidade ou direito ao resguardo tem como fundamento a defesa da per- 
sonalidade humana contra injunções ou intromissões alheias (PAESANI, 2014). No entanto, a privacidade adquiriu um novo significado em relação aos avanços tecnológicos, como se pode ver nas considerações de Paesani (2014, p. 39) quando aborda a privacidade no âmbito cibernético:

Apresenta duas ordens de problemas: o primeiro reporta-se ao respeito à esfera privada alheia que nos conduz no terreno tradicional da tutela da privacidade. $\mathrm{O}$ segundo referese à privacidade de quem se movimenta naquele espaço e, consequentemente, requer o anonimato. Contudo, os dois problemas estão destinados a saberem as consequências que o indivíduo pode ter se for considerada que a sua privacidade está sendo violada por uma informação na rede.

Bittar (2001) acredita que são da personalidade os direitos reconhecidos à pessoa humana tomada em si mesma e em suas projeções na sociedade, previstos no ordenamento jurídico para a defesa de valores inatos ao homem como a vida, a rigidez física, a intimidade, a honra, a intelectualidade e outros.

É nesse pensar que Bittar (2001 apud Vieira; Alves, 2014, p. 2), em destaque, apresenta como direitos da personalidade os seguintes:

Direitos físicos (protege-se o direito à vida, à integridade física, ao corpo e suas partes, à imagem e à voz); direitos psíquicos (abriga-se o direito à liberdade de pensamento, de culto, de expressão e de outras manifestações; inclusive o direito à intimidade, o direito à integridade psíquica e o direito ao segredo); direitos morais (situam-se os direitos à identidade, à honra, à reputação e o direito às criações intelectuais).

Vieira e Alves (2014, p.2) ressaltam que, por serem inatos, os direitos da personalidade "devem ser reconhecidos e sancionados pelo Estado em um outro plano de direito positivado" e, ainda, que se encontram no Código Civil Brasileiro (arts. 11 a 21) alguns direitos da personalidade, “[...] porém outros direitos relacionados com o princípio da dignidade da pessoa humana em suas dimensões física, moral e psíquica com fun- 
damento no direito geral da personalidade devem ser reconhecidos e observados pelos aplicadores do direito".

Desse modo, a proteção do direito à privacidade do indivíduo deve ser vista como um direito fundamental a ser resguardado contra as intromissões dos avanços do mundo moderno tecnológico. Visto que, somente o indivíduo tem o direito de escolher o que terceiro possa saber de sua vida privada.

\section{PRIVACIDADE NAS REDES SOCIAIS COMO COMUNIDADE ONLINE}

As novas tecnologias, desde o ano de 2000, estão assumindo cada vez mais uma dinâmica interativa entre seus usuários, onde a produção de informação não fica monopolizada nos meios de comunicação formais, mais sim integrando ao mundo global.

$\mathrm{O}$ expoente dessa nova era das tecnologias virtuais tem sido as redes sociais que permitem o compartilhamento de ideias e informações entre seus usuários com objetivos e valores comuns. Nesse contexto Castells (1999 apud SLAVOV, 2009) descreve que:

Essas redes sociais tornam-se forma de "comunidades especializadas", isto é, formas de sociabilidade construídas em torno de interesses específicos. Como as pessoas podem facilmente pertencer a várias dessas redes, os indivíduos tendem a desenvolver seus "portfólios de sociabilidade", investindo diferencialmente, em diferentes momentos, em várias redes com diversas pessoas.

As redes sociais são um tipo especial de comunidades online, na qual seus usuários criam um perfil com suas informações pessoais e se conectam com outros usuários, comunicando-se assim uns com os outros. Essas informações que os usuários fornecem geralmente podem ser constituídas por entretenimento, interesses pessoais e profissionais, dados de identificação pessoais e fotos ou vídeos da vida social ou pessoal (SLAVOV, 2009). 
Nesse contexto, um dos maiores problemas com que as pessoas se defrontam nas redes sociais já não é a falta de informação, mas sim a seleção adequada ou filtragem daquela que pode ser efetivamente útil. Isto porque, a cada segundo, milhões de usuários despejam nas redes sociais opiniões, sentimentos, fotos e vídeos, sem ponderar no fator segurança dessas informações, que são essenciais para a preservação da privacidade e dignidade da pessoa humana (SLAVOV, 2009).

Schmidt (2009, p. 84) aduz, com propriedade, que “[...] com um clique no mouse, é possível compartilhar quase tudo fotografias, vídeos, e os pensamentos mais íntimos-com quase todos. Por isso, é fundamental definir novas regras em torno do tema privacidade, para regular um mundo cada vez mais transparente". Já, Graieb (2009, p.81) assevera que:

A violação da privacidade muitas vezes é realizada pela própria vítima, o que pode se chamar de "paradoxo da privacidade", sendo que todos os dias, as pessoas se afligem por estar vulneráveis à espionagem digital. Contundo desvelam sua intimidade on-line ao permitir que desconhecidos tenham acesso a seu computador, em redes sociais, por exemplo, local em que revelam uma larga fatia de sua vida com fotos, depoimentos e vídeos.

Num mundo em que se envia um grande volume de informações pessoais em arquivos digitais, algumas informações que precisam ficar sigilosas podem cair em mãos perigosas. A privacidade online passa então a ser um bem de valor fugaz e inestimável, no qual as pessoas só dão o devido valor quando as perdem (RAMOS, 2009).

\section{IMPACTO DAS REDES SOCIAIS NO COTIDIANO DOS USUÁRIOS}

No entanto, muitos casos de violação do direito à privacidade dos usuários vêm ocorrendo, frequentemente, nas redes sociais no Brasil. Todavia, alguns passam desapercebidos, não 
ganhando tanto destaque nas mídias, pois muitas das pessoas prejudicadas por esta ação preferem não denunciar os invasores, por vergonha de terem sua vida privada exposta ou por não saberem quem são os invasores.

Entre os fatos de violação à privacidade que ocorrem nas redes sociais, pode-se destacar o caso, em 2006, da modelo Danielle Cicarelli e de seu namorado, na época, na qual a modelo ajuizou uma ação contra o site do You Tube, pela exibição de suas imagens e vídeos captados clandestinamente por um paparazzo, durante a prática de ato sexual na praia de Cádiz, na Espanha.

Outro caso que, também teve grande repercussão nacional, foi o da atriz Carolina Dieckmann que, em maio de 2012, teve suas 36 fotos íntimas vazadas na Internet, por hackers que invadiram o seu $e$-mail roubando as fotos e chantageando a atriz pedindo RS 10.000,00 (dez mil reais) para não publicarem as imagens (VALLE, 2013).

Como, na época, não existia uma legislação específica que tratasse sobre a invasão de dispositivo informático, os invasores responderam pelos crimes de extorsão, furto e difamação do Código Penal. Porém, a partir desse fato que foi amplamente divulgado na mídia, o legislador sentindo-se pressionado pelo ocorrido e pela falta de uma legislação que tutelasse os dados informáticos, criou a Lei n. 12.737/2012, apelidada de Lei Carolina Dieckmann, a qual versa sobre a tipificação criminal de delitos informáticos.

Em março de 2013, o ator Murilo Rosa, também teve suas fotos íntimas, na qual aparecia nu, divulgadas nas redes sociais, por meio de hacker, que ainda chegou a chantageá-lo por meio de ligações e torpedos para o seu celular, para não ter as fotos publicadas (VALLE, 2013).

É importante destacar que não são somente as pessoas famosas que têm o seu direito à privacidade violado, as pessoas 
anônimas, também, são vítimas dessa transgressão. Segundo a reportagem do Jornal Diário Catarinense (2013, mês novembro), uma adolescente de 16 anos cometeu suicídio, horas após descobrir que o seu ex-namorado havia espalhado nas redes sociais, especialmente no Twitter e no Facebook, fotos suas seminuas, captadas numa conversa na webcam entre a vítima e o autor, ainda quando eram namorados.

Caso interessante, que chamou a atenção foi o da Jornalista Rosana Hermann, que teve sua senha roubada no Twitter por um hacker que acabou apagando mais de 20 mil postagens, que a própria jornalista tinha registrado na rede sobre diversos assuntos.

É do conhecimento geral que grande parte dos usuários que utilizam as redes sociais estão se expondo excessivamente no ambiente virtual, sem se preocupar com as consequências que esse mundo pode lhe trazer. É preciso refletir que algumas informações inseridas nas redes sociais podem ser usadas ou utilizadas para prejudicar o próprio usuário, pois o grande desafio é saber onde termina o público e começa o privado (RAMOS, 2009).

Segundo o americano Daniel Solove (apud GRAIEB, 2009), autor de diversos livros sobre a privacidade, entre os quais $\mathrm{O} F u-$ turo da Reputação - fofoca, rumores e privacidade na Internet, afirma que "[...] o maior risco da superexposição da intimidade é o arrependimento", pois os usuários ao divulgarem ou compartilharem fotos, vídeos e mensagens sobre sua vida privada nas redes virtuais, acabam passando informações que podem ser acessadas por terceiros mal intencionados que repassam para outras pessoas de forma a denegrir a imagem do usuário.

Assim sendo, observa-se que as redes sociais, isto é, a Internet como um todo, têm forte poder sobre os usuários que as utilizam sem segurança e acabam colocando a sua vida privada em risco, causando muitas vezes, danos e consequências irreparáveis e inestimáveis, assim como nos casos supracitados.

Por outro lado, encontram-se as vítimas de fotos vazadas 
que não sabem a quem recorrer. O compartilhamento de fotos e vídeos íntimos pelo celular, sem autorização, é uma prática cada vez mais comum.

Em depoimento à repórter Luana Lima, do Diário do Nordeste, em julho de 2015, Ana Patrícia (nome fictício) atriz e blogueira diz que, no início de 2010, após colocar o notebook para formatar em uma loja especializada em computadores, não sem antes deletar todos os arquivos que poderiam comprometê-la, começou a passar por uma série de ameaças até ver sua intimidade exposta na Internet. Um ano depois, começou a sofrer ameaças por e-mail, diziam que se não enviasse novas fotos nuas, iriam colocar tudo na $\mathrm{Web}$.

Como as mensagens foram ignoradas passaram a ameaçar seu pai, também por e-mail. Passou a sentir o desprezo de outras mulheres e maior aproximação de homens. Afastou-se de todos, porém um ano depois, teve as contas do Facebook e do e-mail invadidas, só conseguiu recuperá-las algum tempo depois. Mas, mesmo assim, voltou a receber intimidações de um e-mail falso, sempre pedindo mais imagens. Deletou o perfil do Facebook, criou um novo e-mail no fim de 2013. No início de 2014, as fotos começaram a circular por meio do aplicativo WhatsApp. Chegou a procurar a Polícia, advogados, mas nada pode fazer, a não ser ignorar e seguir a vida em frente. No mesmo ano, mudou de cidade, em grande parte por causa do desconforto com toda a situação gerada. A entrevistada - Luana Lima (2015, p. 10) diz: "Não tem como explicar, você se sente incapaz de mãos atadas, porque não tem como descobrir, nem leis específicas e meios. Tudo é muito difícil. É revoltante [...]”. Passados cinco anos, ainda tenta deletar de sua vida o constrangimento pelo qual passou e está mais desconfiada das pessoas.

Os participantes do mundo digitalizado também podem ser vítimas do mesmo mecanismo que lhes traz tantas benesses, daí a necessidade de um limite para a Rede: o limite jurídico que 
precisa ter efetividade, seja de forma micro social, uma codificação firmada por todos os países do globo (CONSALTER, 2008).

\section{PRIVACIDADE E ALEI DO MARCO CIVIL DA INTERNET - LEI N. 12.965/2014}

Com o aumento da popularização da Internet, por todas as classes sociais, cada vez mais presente na vida dos usuários que a utilizam, a todo instante, surge a necessidade de se criar uma legislação que possa regulamentar o uso da Internet, principalmente em relação à privacidade das informações que são publicadas ou compartilhadas pelos próprios usuários ou por terceiros mal-intencionados.

É importante destacar que no Brasil, até o ano de 2014, não havia norma específica que assegurasse a privacidade das informações dos usuários que navegam no mundo virtual. Porém, existiam diversas leis esparsas sobre vários aspectos pontuais que envolvem a Internet, como por exemplo, a Lei $\mathrm{n}$. 9.609/98 (Lei de Software), a Lei n. 12.735/12 (Lei Azeredo), a Lei n. 12.737/12 (Lei Carolina Dieckmann) e o Decreto n. 7.962/13 (Regulamento do Comércio Eletrônico).

Dessa forma, nos conflitos que envolvessem a violação da privacidade das informações dos usuários nas redes virtuais, aplicava-se por analogia o inciso X, do art. $5^{\circ}$ da Constituição Federal de 1988, por não existir uma lei específica que pudesse solucionar os conflitos existentes que ocorrem através do ambiente virtual.

Diante disso, nasce coma aprovação do Congresso Nacional, no dia 25 de março de 2014, a Lei n. 12.965/2014, conhecida popularmente como o Marco Civil da Internet, com a finalidade de regulamentar o uso da Internet no Brasil, para preencher o vazio legislativo que existia no ordenamento jurídico Brasileira sobre o assunto.

A Lei n. 12.965/2014 foi promulgada no dia 23 de abril de 
2014, tendo como objetivo solucionar problemas que envolvem a inviolabilidade do direito à privacidade e à proteção de dados pessoais, nos quais acontecem frequentemente no cotidiano dos usuários que utilizam os serviços disponíveis na rede mundial de computadores.

O Marco Civil da Internet traz como pedra fundamental o princípio da privacidade. Nesse sentido vale destacar no art. $3^{\circ}$ o seguinte: proteção da privacidade; inviolabilidade da intimidade e da vida privada; inviolabilidade ao sigilo do fluxo de suas comunicações; inviolabilidade ao sigilo de suas comunicações privadas armazenadas e outros.

No art. $8^{\circ}$ encontra-se a garantia do direito à privacidade [...] No art. $10^{\circ}$ contém a guarda e a disponibilização dos registros de conexão e de acesso a aplicações da Internet de que trata esta Lei, bem como de dados pessoais e do conteúdo de comunicações privadas, devem atender à preservação da intimidade, vida privada, honra e imagem das partes direta ou indiretamente.

A estrutura presente na Lei n. 12.965/2014 - Marco Civil da Internet, está pautada em três pilares: a proteção à vida privada, a liberdade de expressão e a neutralidade da rede. A proteção à privacidade consiste como um dos princípios essenciais para o uso da Internet e norteadores para proteção dos usuários, como se observa no inciso II, do art. $3^{\circ}$, da mencionada Lei: "A disciplina do uso da internet no Brasil tem os seguintes princípios: [...] proteção da privacidade"(BRASIL, 2014).

$\mathrm{O}$ art. $7^{\circ}$, inciso $\mathrm{I}$, da referida Lei, aduz: “o acesso à Internet é essencial ao exercício da cidadania, e ao usuário são assegurados os seguintes direitos: [...] inviolabilidade da intimidade e da vida privada, sua proteção e indenização pelo dano material ou moral de sua violação [...]" (BRASIL, 2014). Esse artigo reproduz o disposto no art. $5^{\circ}$, inciso X, da Constituição Federal, que assegura aos indivíduos a proteção a inviolabilidade de sua 
privacidade, garantindo assim em caso de violação indenização pelos danos ocasionados.

Na mesma seara de proteção à privacidade, no art. $8^{\circ}$, a Lei n. 12.965/2014 está previsto que: "a garantia do direito à privacidade [..] nas comunicações é condição para o pleno exercício do direito de acesso à Internet" (BRASIL, 2014). Observa-se que esse artigo se encontra em redundância com o art. $3^{\circ}$ da Lei, que já reconhece a garantia da privacidade. Nesse sentido, Tomasevicius Filho (2014, p.162) afirma que essa redundância "se dá pela enorme dificuldade da regulamentação jurídica em tutelar a privacidade na Internet, pois a tônica desta Lei foi a de usar e abusar das repetições em seu texto".

Em relação as comunicações privadas do usuário na rede virtual o art. 10 da Lei n. 12.965/2014 dispõe que:

A guarda e a disponibilização dos registros de conexão e de acesso a aplicações de internet de que trata esta lei, bem como de dados pessoais e do conteúdo de comunicações privadas, devem atender à preservação da intimidade, da vida privada, $[\ldots]$ das partes direta ou indireta envolvidas.

De acordo com este artigo as comunicações privadas dos usuários devem ser preservadas de forma que o conteúdo das informações não esteja disponível a terceiros, a não ser mediante autorização judicial.

$\mathrm{O}$ art. 11, do Marco Civil da Internet, indica que:

Em qualquer operação de coleta, armazenamento, guarda e tratamento de registros, de dados pessoais ou de comunicações por provedores de conexão e de aplicações de internet em que pelo menos um desses atos ocorra em território nacional, deverão ser obrigatoriamente respeitados a legislação brasileira e os direitos à privacidade [...] e aos sigilos das comunicações privadas [...]

Para Tomasevicius Filho (2014, p.164), o art. 11 da Lei mostra a "falência" da regulação da privacidade na Internet, uma vez que se procurou conferir aplicação extraterritorial à 
proteção da vida privada dos usuários brasileiros. No entanto, tal norma não tem como ser aplicada, visto que os principais mecanismos de busca, servidores de e-mails e páginas das redes sociais estão situados nos Estados Unidos, em face dos quais o Brasil não tem jurisdição.

De fato, a Lei n. 12.965/2014 revela-se como uma referência global, fixando um marco histórico e jurídico de utilização da Internet no Brasil, aplicando-se a todas as situações em que a privacidade do usuário na rede esteja em risco. No entanto, verifica-se que, mesmo com o advento desta Lei não se consegue resolver algumas lacunas que ela apresenta, como por exemplo, a proteção dos dados pessoais nas plataformas eletrônicas.

É importante destacar que se encontra em tramite no Senado Federal o projeto de Lei n. 181/2014, apresentado pelo senador Vital do Rêgo (PMDB/PB), o qual trata da proteção dos dados pessoais na Internet, com a finalidade de proteger à privacidade e controlar a circulação das informações nas redes virtuais do país, em virtude de solucionar algumas lacunas deixadas pela Lei do Marco Civil da Internet.

Todavia, segundo a revista Consultor Jurídico, o referido projeto já começou a gerar um intenso debate durante as audiências públicas na Comissão de Constituição e Justiça e Cidadania (CCJ) do senado, no dia 2 de dezembro de 2014, devido as críticas sobre alguns pontos do texto da Lei, dentre os quais encontrar equilibrar a proteção da privacidade, que é um valor essencial para o indivíduo, com a necessidade de reconhecer que o processamento de dados é hoje um indicador econômico de desenvolvimento para qualquer país. Vale ressaltar, que até o termino desse artigo, em 2016, o projeto de Lei n. 181/2014 encontrava-se em tramitação na Comissão de Assuntos Econômicos (CAE) do Senado Federal.

Assim sendo, a Lei n. 12.965/14 foi considerada como um 
marco histórico e jurídico na sociedade cibernética, pelo fato de tentar trazer mais segurança jurídica aos usuários que navegam no ambiente virtual, garantindo ainda, a proteção do direito da privacidade das informações nesse ambiente, uma vez que não existe uma norma específica que trata sobre o assunto. Porém, ainda está longe de ser uma solução para os problemas ocorrentes no mundo cibernético.

\section{DIREITO À PRIVACIDADE NA JURISPRUÊNCIA BRASILEIRA}

Convém expor como os tribunais brasileiros estão julgando os processos acerca da proteção da privacidade no mundo cibernético, como mostram os julgados que se considera interessante destacar:

A $5^{\text {a }}$ Câmara Cível do Tribunal de Justiça do Rio Grande do Sul, tem entendido que a divulgação de fotografias pessoais do usuário na Internet, sem a sua autorização, expondo o mesmo à situação vexatória, afronta o direito fundamental da privacidade:

Ementa: AÇÃO DE REPARAÇÃO DE DANOS MORAIS. RESPONSABILIDADE CIVIL. RELACIONAMENTO AMOROSO ENTRE ADOLESCENTE. REMESSA DE FOTOGRAFIAS VIA INTERNETCOM AUTORANUA. DIVULGAÇÃO. AUSÊNCIA DE AUTORIZAÇÃO. EXPOSIÇÃO VEXATÓRIA. VIOLAÇÃOÀ IMAGEM E DA PRIVACIDADE. DANO MORAL CARACTERIZADO. MANUTENÇÃO DO VALOR. JUROS MORATÓRIOS. ATO ILÍCITO. (BRASIL. Apelação Cível n. 70062581327/RS. Relator: Jorge André Pereira Gailhard. Órgão Julgador: Quinta Câmara Cível. DJ: 27/05/2015-grifo nosso).

A Apelação Cível n. 2012.003989-5/0000-00/MS, trata da divulgação de fotos íntimas na Internet da ex-noiva do autor do ato, na qual o mesmo foi condenado ao pagamento de indenização por danos morais no valor de RS 5.000,00, uma vez que esse ato violou o direito à imagem, à privacidade, à 
honra da vítima:

Ementa: APELAÇÃO CÍVEL- AÇÃO DE INDENIZAÇÃO POR DANOS MORAIS - DIVULGAÇÃO DE FOTOGRAFIAS ÍNTIMAS DE EX NOIVA NA INTERNET - AUSÊNCIA DE CONSENTIMENTO - PROVA DOCUMENTAL NÃO DESCONSTITUÍDO-OFENSA À IMAGEM - DIREITO AUTÔNOMO - DANO MORAL PRESUMIDO - DESNESSIDADE DE COMPROVAÇÃO - RECURSO CONHECIDO E IMPROVIDO (BRASIL- Apelação Cível n. 2012.003989-5/MS, Relator Des. Sideni Soncini Pimentel, Órgão Julgador: $5^{\circ}$ Câmara Cível. DJ: 01/03/2012 - grifo nosso).

Outro caso interessante referente a divulgação de fotos íntimas na rede social, que violam os direitos fundamentais, foi decidido pela $23^{\circ}$ câmara Cível/Consumidor do Tribunal de Justiça do Rio de Janeiro, que condenou o réu a pagar RS $8.000,00$ reais por dano moral à vítima e ainda que fosse retirado o conteúdo ofensivo do ar, no que dispõe:

Ementa: AÇÃO DE RITO ORDINÁRIO. DIREITO DO CONSUMIDOR. CRIAÇÃO DE PERFIL FALSO COM NOME DA AUTORA EM REDE SOCIAL. DIVULGAÇÃO DE FOTOS INTIMAS QUE VIOLAM DIREITOS FUNDAMENTAIS DA AUTORA, TAIS COMO A IMAGEM E AVIDA PRIVADA. DESIDIA DA RE EM RETIRAR O CONTEUDO OFENSIVO DO AR. DANO MORAL CONFIGURADO. MAJORAÇÃO DO QUANTUM INDENIZATORIO PARA R \$ 8.000,00 REAIS. CABIMENTO, NA HIPOTESE, DO JULGAMENTO MONOCRATICO. PROVIMENTO DO APELO DA AUTORA E DESPROVIMENTO DO APELO DA RÉ (BRASIL-APL 00595023920128190002/RJ, Relator Des. Sergio Ricardo de Arruda Fernandes, Órgão Julgador: $23^{\circ}$ Câmara Cível/Consumidor. DJ: 07/04/2015 - grifo nosso).

No Recurso Especial n. 1306157/SP, o Superior Tribunal de Justiça afirmou que os vídeos divulgados na rede social YouTu$b e$, no qual ofendia à imagem da vítima deveria ser retirado do ar no prazo de 24 horas sob multa no valor de $\mathrm{R} \$ 500,00$ reais 
por dia de descumprimento.

Ementa: DIREITO CIVIL. OBRIGAÇÃO DE FAZER E NÃO FAZER. VÍDEOS DIVULGADOS EM SITE DE COMPARTILHAMENTO (YOUTUBE). CON-TRAFAÇÃO A ENVOLVER A MARCA E MATERIAL PUBLICITÁRIO DOS AUTORES. OFENSA À IMAGEM E AO NOME DAS PARTES. DEVER DE RETIRADA. INDICAÇÃO DE URL'S. DESNECESSIDADE. INDIVIDUALIZA-ÇÃO PRECISA DO CONTEÚDO DO VÍDEO E DO NOME A ELE ATRIBUÍDO. MULTA. REFORMA. PRAZO PARA A RETIRADA DOS VÍ-DEOS (24 H). MANUTENÇÃO (BRASIL- Resp n. 1306157/SP, Relator Min.Luis Felipe Salomão, Órgão Julgador: Quarta Turma, DJ: 17/12/2013-grifo nosso).

Diante dos julgados mencionados, conclui-se que, quase todos os casos que envolvem a violação do direito da privacidade nas redes sociais são tratados como danos morais, principalmente quando envolvem divulgação de fotos ou vídeos que comprometam a vida privada dos usuários.

\section{CONCLUSÃO}

Diante do exposto, o presente trabalho teve por finalidade abordar o estudo do direito fundamental da privacidade, consagrado no art. $5^{\circ}$, inciso $X$ da Constituição Federal de 1988, considerando as ameaças que o mundo cibernético pode provocar em relação às informações/dados pessoais que neste circulam, quando os mesmos são invadidos por terceiros mal-intencionados que acabam causando sérios danos aos usuários dessas informações.

Nesse contexto, observou-se que com as redes sociais cada vez mais presentes na vida cotidiana dos usuários, aumentou também, o risco de invasão das informações privadas das pessoas que publicam fotos, vídeos e mensagens pela Internet, causando na maioria das vezes danos irreparáveis e inestimáveis.

Para tentar solucionar esses riscos de violação da privaci- 
dade pela Internet foi criada a Lei n. 12.965/2014, conhecida como o Marco Civil da Internet, sendo considerada um marco importante para o mundo virtual, adentrando no ordenamento jurídico brasileiro com a missão de regulamentar o uso da Internet no Brasil, em virtude de que até o presente momento não existia uma legislação específica que versasse sobre o assunto.

Apesar da Lei n. 12.965/2014 ter se revelado como um marco histórico e jurídico no Brasil, por ter regulamentado o uso da Internet no Brasil com a finalidade de proteger a privacidade dos usuários contra os riscos encontrados nas redes digitais, verifica-se que ainda existem lacunas em relação à privacidade dos usuários na Internet. Uma vez que, alguns artigos da Lei, como por exemplo o art. $7^{\circ}$, inciso I, reproduz o que dispõe o art. $5^{\circ}$, inciso $\mathrm{X}$ da Constituição Federal, sem trazer nenhuma inovação que poderia torna-la a lei mais eficiente quanto a privacidade.

Constatou-se, ainda que os Tribunais Brasileiros vêm tratando dos casos de invasão do direito à privacidade dos usuários na Internet, como danos morais, não aplicando os artigos da Lei do Marco Civil da Internet que asseguram a proteção à privacidade dos usuários, além de solicitarem a remoção do conteúdo ofensivo, sob pena de multa, por dia, caso o mesmo não seja retirado.

Analisou-se que no mundo virtual, no qual as informações são expostas numa velocidade de um clique, é preciso que os usuários tenham mais precaução e cuidado em relação a tudo que os mesmos divulgam na Internet, pois essas informações podem ser usadas contra si mesmo, ocasionando violação à privacidade das pessoas e, muitas vezes, trazem danos constrangedores para a vida das mesmas.

Com todos os aspectos demonstrados na pesquisa, acredita-se que os usuários precisam se conscientizar que quanto mais avança a tecnologia, mais a privacidade deles será devassada. No entanto, todo esse risco que o mundo virtual pode provocar na vida dos usuários não deve ser encarado 
como desprotegido pelo ordenamento jurídico brasileiro. Visto que, atualmente já se tem a Lei n. 12.965/204 que assegura a proteção à privacidade dos usuários no ambiente digital, e as jurisprudências dos tribunais brasileiros.

Todavia, é muito importante que os próprios usuários criem o hábito de monitorar e preservar a divulgação de suas informações pessoais (textos, dados, imagens e vídeos) para que, no caso de alguma invasão realizada contra essas informações, seja possível identificar o conteúdo ilícito visando, assim, retirá-lo rapidamente de circulação como forma de minimizar o dano sofrido.

\section{REFERÊNCIAS}

ASSIS, José Francisco de. Direito à privacidade no uso da internet: omissão da legislação vigente e violação ao princípio fundamental da privacidade. Internet e Informática. Revista Ambito Jurídico. Disponível em: < http://www.ambito-juridico.com.br/site/ $\mathrm{n}$ _link=revista_artigos_leitura\&artigo_id=12848>. Acesso em: 24 maio 2015.

BASTOS, Celso Ribeiro. Curso de direito constitucional. 2. ed. São Paulo, 2000.

BITTAR, Carlos Alberto. Os direitos da personalidade. 5. ed. Rio de Janeiro: Forense Universitária, 2001, pp. 64-65.

BRASIL. Código civil brasileiro. 2. ed. Brasília, DF, 2008. Disponível em: $<$ http:// www2.senado.leg.br/bdsf/bitstream/handle/id/70327/C\%C3\%B3digo\%20Civil\%20 2\%20ed.pdf?sequence=1>. Acesso em: 27 maio 2015.

. Código penal brasileiro. Disponível em: <http://www.planalto.gov.br/ ccivil_03/decreto-lei/Del2848compilado.htm. Acesso em: 22 maio 2015.

. Constituição de 1988. Constituição da República Federativa do Brasil, Brasília, DF, Senado, 1988.

. Decreto n. 7.962, de 15 de março de 2013. Regulamenta a Lei n. 8.078, de 11 de setembro de 1990, para dispor sobre a contratação no comércio eletrônico. Disponível em: <http://www.planalto.gov.br/ccivil_03/_ato2011-2014/2013/decreto/ d7962. htm>. Acesso em: 20 maio 2014.

. Lei n. 9.609, de 19 de fevereiro de 1998. Dispõe sobre a proteção da propriedade intelectual de programa de computador, sua comercialização no País, e dá outras providências. Disponível em: <http://www.planalto. gov.br/ccivil_03/Leis/L9609. htm>. Acesso em: 20 maio 2014.

. Lei n. 12.735, de 30 de novembro de 2012. Altera o Decreto-Lei no 2.848, de 7 de dezembro de 1940-Código Penal, o Decreto-Lei no 1.001, de 21 de outubro de 1969-Código Penal Militar, e a Lei no 7.716, de 5 de janeiro de 1989, para tipificar condutas realizadas mediante uso de sistema eletrônico, digital ou similares, que sejam praticadas contra sistemas informatizados e similares; e dá outras providências. Dis- 
ponível em: <http://www.planalto.gov.br/ccivil_03/_Ato2011-2014/2012/Lei/L12735. htm>. Acesso em: 22 maio 2014.

. Lei n. 12.737, de 30 de novembro de 2012. Dispõe sobre a tipificação criminal de delitos informáticos; altera o Decreto-Lei no 2.848, de 7 de dezembro de 1940Código Penal; e dá outras providências. Disponível em: <http://www.planalto.gov.br/ ccivil_03/_ato2011-2014/2012/lei/112737.htm>. Acesso em: 20 maio 2014.

Lei n. 12.965, de 23 de abril de 2014. Estabelece princípios, garantias, direitos e deveres para o uso da Internet no Brasil. Disponível em: <http://www.planalto.gov.br/ ccivil_03/_ato2011-2014/2014/lei/112965.htm>. Acesso em: 20 maio 2014.

. Projeto Lei n. 2.126, de24 de agosto de 2011. Estabelece princípios, garantias, direitos e deveres para o uso da Internet no Brasil. Disponível em: $<$ http://www.camara. gov.br/sileg/integras/912989.pdf>. Acesso em: 20 maio 2014.

. Projeto de Lei n. 181, 21 e maio de 2014. Estabelece princípios, garantias, direitos e obrigações referentes à proteção de dados pessoais. Disponível em: $<$ http://www.senado.gov.br/atividade/materia/getPDF.asp?t=150798\&tp=1>. Acesso em: 20 maio 2014. CÂMARA DOS DEPUTADOS. Marco civil da internet ganha urgência constitucional na tramitação. Disponível em: <http://www2.camara.leg.br/ camaranoticias/noticias/ COMUNICACAO/451694-MARCO-CIVIL-DA-INTERNET-GANHA-URGENCIA-CONSTITUCIONAL-NA-TRAMITACAO.html>. Acesso em: 07 mar. 2014.

CONSALTER, Zilda Mara. Direito à privacidade e a internet: linhas sobre a atual questão indenitária. In: Âmbito Jurídico, Rio Grande, XI, n. 51, mar 2008. Disponível em: <http://www.ambito-juridico.com.br/site/index.php?n_link=revista_artigos_\%20 leitura\&artigo_id=2456> Acesso em: 20 maio 2014.

DIÁRIO CATARINENSE ONLINE. A adolescente de 16 anos do Rio Grande do Sul se suicida após ter fotos intimas divulgadas na internet. Florianópolis, 19 jan. 2013. Disponível em <http://www. diariocatarinese.com.br>. Acesso em: 13 maio 2015.

DIÁRIO DO NORDESTE ONLINE. É possível rastrear origem do conteúdo. Fortaleza, 19.07.2015. Disponível em: <http://diariodonordeste.verdesmares.com.br/ cadernos/ cidade/e-possivel-rastrear-origem-do-conteudo-1.1341838> . Acesso em: 20 jul. 2015.

GRAIEB, Carlos. Quando não há mais segredos. Revista Veja, n. 32, p. 81, ago. 2009. MACEIRA, Irma Pereira. A proteção do direito à privacidade familiar na internet. 2012. Tese (Doutorado em Ciências Sociais). Pontifícia Universidade Católica de São Paulo. São Paulo, 2012.

MARCO civil da internet e proteção de dados pessoais vão a debate. NET. Revista Consultor Jurídico. 27 jan. 2015. Disponível em <http://www.conjur.com.br>. Acesso em: 01 jul. 2015.

MARQUES, Andréa Neves Gonzaga. Direito à intimidade e privacidade. Jus Vigilantibus, Vitória, fev. 2008. Disponível em: <http://jusvi.com/artigos/31767>. Acesso em: 19 out. 2015.

PAESANI, Liliana Minardi. Direito e internet: liberdade de informação, privacidade e responsabilidade civil. 7. ed. São Paulo: Atlas, 2014.

RAMOS, Tagil Oliveira. Especial privacidade: ela acabou. E agora? Nov 2009. Disponível em: <http://www.itweb.com.br/noticias>. Acesso em: 23 maio 2015.

SCHMIDT, Eric. O desafio de criar novas regras. Revista Veja, São Paulo, n. 32, p. 84, ago. 2009. 
SLAVOV, BÁRBARA. Os limites do uso do desenvolvimento tecnológico frente aos direitos de privacidade. 2009. Dissertação (Mestrado em Direito). Centro Universitário Fieo, Osasco, 2009.

TOMASEVICIUS FILHO, Eduardo. Em direção a um novo 1984? A tutela da vida privada entre a invasão de privacidade e a privacidade renunciada. Revista da faculdade de direito da Universidade de São Paulo, São Paulo, v.109, p.129-169, jan/dez. 2014.

VALLE, James Della. Lei Carolina Dieckmann entra em vigor nesta terça-feira. Revista Veja on-line. Tecnologia. Editora Abril, abr. 2013. Disponível em: $<$ http://veja.abril.com.br/tecnologia/lei- carolina-dieckmann-entra-em-vigor-nesta-terca-feira/> Acesso em: 27 maio 2015.

VIEIRA, Alexandre Pires; ALVES, José Cláudio Rodrigues. $O$ direito à privacidade frente aos avanços tecnológicos na sociedade da informação. Disponível em: <http:// jus.com.br/artigos/27972/o-direito-a-privacidade-frente-aos-avancos-tecnolo-gicos--nasociedade-da-informacao/2\#ixzz3K70lVeRz>. Acesso em: 20 nov. 2014.

Artigo recebido em: 30/05/2017

Artigo aprovado em: 06/10/2017 